\title{
The Transposable Limits of Open Design for Sustainable Development
}

\section{SIGRADI2018 TECHNOPOLITICAS \\ xxii congresso da sociedade iberoamericana de gráfica digital 22th conference of the iberoamerican society of digital graphics 07|08|09|novembro|2018 iau usp | são carlos | sp br}

\author{
Rodrigo Argenton Freire \\ University of Campinas | Brazil | r.freire@fec.unicamp.br
}

Evandro Ziggiatti Monteiro

University of Campinas | Brazil | evandrozig@fec.unicamp.br

\begin{abstract}
In this study, we defined a set of parameters to evaluate openness, social inclusiveness, economic viability and environmental responsibility in Open Design (OD) Projects. We compared the parameters of eight OD cases of different nature and scale related to the built environment. We identified current limitations to the application of OD in developing countries and developed a set of recommendations to improve openness and guarantee sustainable practices. Results show that social inclusiveness is limited to the existence of digital fabrication tools and collaboration platforms, there is a lack of information concerning environmental aspects and there are positive perspectives for local businesses and job creation.
\end{abstract}

Keywords Open Design, Democratic Design, Open Hardware, Open Architecture

\section{INTRODUCTION}

Following the success of the Open Source Movement (OSM) as an alternative for innovation processes and businesses within the software communities, other initiatives and definitions were created in order to broaden the reach of the philosophy behind the OSM. The concept of Open Design (OD) is one example of such derivatives. It refers to the possibility of applying the Open Source model to the development of hardware components tangible products (Raasch, Herstatt, \& Balka, 2009; Fjeldsted et al., 2012). Most of the OD benefits are linked to its possibility of providing democratization of the design process (von Hippel, 2005; Kwon \& Lee, 2017), faster and better innovation processes (Vallance, Kiani, \& Nayfeh, 2001; Shah, 2008), and citizen empowerment (Nascimento, 2014). In addition, OD is also seen as a promoter of sustainable consumption and production (Kohtala 2015; Bonvoisin, 2016). However, little has been explored regarding the use of OD to promote sustainability in developing countries. In order to evaluate whether such benefits of OD are valid we analyze the existing barriers to its widespread adoption.

Although there is no definitive definition to Open Design, there is a consensus that the it refers to a gradual condition (Open Knowledge Foundation, 2012; Boisseau, Omhover, \& Bouchard, 2018). Openness can vary (i) at the design process, from non-collaborative to fully collaborative; (ii) at the format of the shared documentation format, from making it available on the web in any format to using only non-proprietary formats; and, (iii) at the license type, from publishing into public domain to maintaining the original author's rights. We articulate openness principles to existing studies in OD.
West and O'mahony (2008) distinct transparency from accessibility as two distinct forms of openness. Accessibility is related to easiness of access to source documentation and the possibility given to users to actively contribute to a design project. Transparency refers to the full documentation of a design process to allow users to understand "what is happening and why" (West and O'mahony, 2008). Balka (2011 p.82) introduces the importance of "Replicability" as an aspect of openness. The understanding is that a design is not open if the required components to assemble a product are not available. In this sense, a fully replicable design focus on the use of components that are easy to obtain and does not demand high skilled knowledge. In this sense, OD should guarantee that anyone, professional or amateur, is able to reproduce, optimize and customize such projects. Lastly, design replication is not sufficient if it cannot be modified and adapted for a different context. We argue that a modular approach enables modification. In fact, the concept of modularization is already considered a driver for Mass Customization, Personalization and Co-creation (Nielsen et al., 2011), problem solving (Afuah \& Tucci, 2012) and to OD (Bonvoisin, 2016). It contributes to collaborative processes by enabling the user/contributor to focus on very specific aspects of the design (Bonaccorsi \& Rossi, 2003; Narduzzo \& Rossi, 2008), usually on what he is most familiar with.

The four above-mentioned aspects: transparency, accessibility, replicability and modularity are not only complementary to the OD definition but essential principles to its application. In developing countries, there is limited access to technologies, materials and tools. 
Under such conditions, the potential of OD to promote design democratization is questionable. For example, is it economically viable to produce an OD projects based on $3 \mathrm{D}$ Printing and CNC-Milling if the required digital fabrication tools are not locally available or require high financial investments? We are aware that $O D$ is not intended to solve issues on local access to technologies. However, studies present local spaces for community production, such as Fablabs and Makerspaces, as alternatives to increase decentralized forms of production (Nascimento, 2014; Hyysalo et al., 2014).

In terms of sustainability we propose to look into it by adopting the triple bottom line framework of sustainable development. The framework refers to the environmental, social and economic dimensions (Elkington, 1998). We adopt the Sustainable Development Goals (SDGs) (United Nations, 2015) to address the three dimensions of sustainable development with a more proactive approach (Levänen, Hossain \& Lyytinen, 2016). Each of the 17 Goals have targets oriented to specific actions such as to (1) ensure access to water, energy and food, (2) reduce inequalities, (3) promote sustainable consumption and (4) promote decent work and innovation.

In this study, we address the gap related to the adoption of $\mathrm{OD}$ in developing countries by considering both openness principles and sustainability indicators. Next, we introduce the methodological approach used to (1) define sustainable indicators and openness principles, (2) select the OD cases and (3) analyze the respective cases. A list of recommendations for enabling $O D$ practice in a developing country context is presented and discussed.

\section{DATA AND METHODS}

In this study, we focus on the strengths and weaknesses of OD to promote social inclusiveness (SI) while guaranteeing economic viability (EV) and environmental responsibility (ER). For this purpose, we adopt nine indicators distributed in two sets. The first set measures openness aspects based on four Open Design principles discussed in the literature. The principles consist on accessibility, transparency, modularity and replicability. The second set incorporates part of the Sustainable Development Goals (SDGs) to measure the abovementioned aspects of SI, EV and ER. Five indicators are used in this case. The indicators are related to two temporal constraints. First, we introduce a critical view on the present limitations for OD and, second, we develop possible pathways for addressing such limitations. It is important to note that the indicators are not specific to each of the sustainability aspects but present overlapping relations. The stimulation of local companies for instance, has environmental impacts (decreasing the need for transportation) and provides better opportunities (social and economic). We adopt a similar approach to studies on frugal innovations (Levänen, Hossain \& Lyytinen, 2016), and Do-it-Yourself production (Bonvoisin \& Prendeviile, 2017). Table 1 introduces the sustainability indicators, the openness principles and the reasoning we adopted to analyze the selected cases.
Table 1 - The selected indicators to measure sustainability and openness of OD projects.

$\begin{array}{ll}\begin{array}{l}\text { Sustainability } \\ \text { Indicators }\end{array} & \text { Reasoning } \\ \begin{array}{l}\text { Does it require } \\ \text { specialized skills for }\end{array} & \begin{array}{l}\text { The need for specialized skills } \\ \text { implementation? }\end{array} \\ \begin{array}{l}\text { decreases social inclusiveness. } \\ \text { SDG 4,5 and 8. }\end{array}\end{array}$

Does it stimulate the creation of local jobs and companies?

It stimulates better job opportunities and higher income. SDGs 1, 5, 8 and 10.

Does it improve access to basic services, (water energy and food)?

It helps to overcome the lack of infrastructure for basic sanitation. SDGs 2, 6, 7 and 9 .

Does it stimulate

sustainable

consumption of

natural resources?

It minimizes the exploitation of natural resources. SDGs 9, 12, 14 and 15.

Does it increase energy efficiency?

It reduces the consumption of nonrenewable resources and $\mathrm{GHG}$ emissions. SDGs 7, 9,12 and 15 .

\section{Openness Principles}

Accessibility

It relates to the easiness of access to the source file, especially, in nonproprietary formats. It also denotes the possibility of users to actively contribute to the development of an OD project.

Transparency

It relates to the full documentation of a design process in order to allow contributors/users to understand "what is happening and why" (West and O'Mahony 2008).

Replicability

It relates to the possibility of reproducing a physical artefact using similar settings as of the original design.

Modularity

It contributes to collaborative processes enabling the user/contributor to focus on very specific aspects of the design.

\section{SELECTION OF CASES}

The selection of the cases consisted on a four-round process. Although OD examples exist in many industries, such as clothing, biotechnology and pharmaceuticals industries (Lakhani \& Panetta, 2007), we limited the cases to the field of architecture and urban design. First, we searched existing literature on OD cases in Scopus, Google Scholars and Web of Science databases. However, we were not able to find a consistent number of cases. Second, we decided to search the web for projects, repositories or companies focused on OD. This search resulted in a higher number of results and 21 potential cases were identified. The third stage, involved a pre-analysis of each case and a grouping process. We developed four major groups considering the scale and nature of each case and the information available. Finally, 
we selected two cases of each group and proceeded to the evaluation stage. It is important to highlight that besides the 21 cases we identified, other examples were found in repositories for sharing design projects. We excluded such examples from our analysis because we aimed at reliable and well-structured cases. Table 2 presents the 21 cases identified and the 8 cases selected. Next, we introduce the grouping process and the evaluation tools we adopted.

Table 2 - List of the 21 OD cases identified and the 8 selected cases (bolded).

\begin{tabular}{|c|c|c|}
\hline Cases & Source & Sector \\
\hline OpenDesk & https://www.opendesk.cc & $\begin{array}{l}\text { Furniture } \\
\text { Design }\end{array}$ \\
\hline $\begin{array}{l}\text { Mozilla } \\
\text { Factory } \\
\text { Space }\end{array}$ & $\begin{array}{l}\text { http://os- } \\
\text { furnitures.tumblr.com }\end{array}$ & $\begin{array}{l}\text { Furniture } \\
\text { Design }\end{array}$ \\
\hline MonoDesign & https://monodesign.com.br & Furniture Design \\
\hline $\begin{array}{l}\text { Dosuno } \\
\text { Design }\end{array}$ & $\begin{array}{c}\text { http://www.dosunodesign.co } \\
\text { m }\end{array}$ & Furniture Design \\
\hline $\begin{array}{l}\text { Open } \\
\text { structures }\end{array}$ & http://openstructures.net & Furniture Design \\
\hline $\begin{array}{l}\text { Home- } \\
\text { Assistant }\end{array}$ & $\begin{array}{l}\text { https://www.home- } \\
\text { assistant.io }\end{array}$ & $\begin{array}{c}\text { Home } \\
\text { Automation }\end{array}$ \\
\hline Calaos & https://www.calaos.fr/fr/ & $\begin{array}{c}\text { Home } \\
\text { Automation }\end{array}$ \\
\hline Domoticz & http://www.domoticz.com & $\begin{array}{c}\text { Home } \\
\text { Automation }\end{array}$ \\
\hline $\begin{array}{l}\text { Open } \\
\text { Hardware }\end{array}$ & $\begin{array}{c}\text { https://www.openhardware.i } \\
\text { o }\end{array}$ & $\begin{array}{c}\text { Home } \\
\text { Automation }\end{array}$ \\
\hline Openmotics & https://up.openmotics.com & $\begin{array}{l}\text { Home Appliance } \\
\text { / Automation }\end{array}$ \\
\hline $\begin{array}{l}\text { Open Energy } \\
\text { Monitor }\end{array}$ & $\begin{array}{c}\text { https://openenergymonitor.o } \\
\text { rg }\end{array}$ & Home Appliance \\
\hline Faircap & http://faircap.org & $\begin{array}{c}\text { Water } \\
\text { Consumption }\end{array}$ \\
\hline $\begin{array}{l}\text { Caminos de } \\
\text { Agua }\end{array}$ & $\begin{array}{l}\text { http://www.catis- } \\
\text { mexico.org }\end{array}$ & $\begin{array}{c}\text { Water } \\
\text { Consumption }\end{array}$ \\
\hline $\begin{array}{l}\text { One } \\
\text { Community }\end{array}$ & $\begin{array}{l}\text { https://www.onecommunityg } \\
\text { lobal.org }\end{array}$ & $\begin{array}{l}\text { Energy-Food- } \\
\text { Water Nexus }\end{array}$ \\
\hline Sunzilla & https://sunzilla.de & $\begin{array}{l}\text { Energy } \\
\text { generation }\end{array}$ \\
\hline Aker & https://akerkits.com & Food Growing \\
\hline $\begin{array}{l}\text { Open } \\
\text { Agriculture } \\
\text { Initiative }\end{array}$ & $\begin{array}{c}\text { https://www.media.mit.ed } \\
\text { u/groups/open- } \\
\text { agriculture- } \\
\text { openag/overview/ }\end{array}$ & Food Growing \\
\hline Elemental & http://www.elementalchile.cl & Housing projects \\
\hline Paperhouses & http://paperhouses.co & Housing Projects \\
\hline Wikihouse & https://wikihouse.cc & Housing Projects \\
\hline Bricksource & $\begin{array}{l}\text { Parametric brickwork } \\
\text { patterns }\end{array}$ & Facade Design \\
\hline
\end{tabular}

The component scale refers to any element that cooperates or works together with other elements to form a system. In this sense, a window, a door or a roof constitute a system and a wood frame, a lock and a tile are some of the components of these systems. The system/organizational scale consists on the scale where general and broader functions of a building are performed. At this scale, the user is indirectly connected to the function, although benefiting from it. The enclosure of a building, for example, separates the exterior from the interior of a building. Table 3 summarizes the selected cases, their domains and general information.

Table 3 - Summary of the domains each case relates to

\begin{tabular}{|c|c|c|c|c|}
\hline Cases & & Domain & & Description \\
\hline & Digital & $\begin{array}{l}\text { Physical } \\
\text { Component }\end{array}$ & $\begin{array}{l}\text { Physical } \\
\text { System }\end{array}$ & \\
\hline OpenDesk & & & $x$ & Furniture Designs \\
\hline $\begin{array}{l}\text { Mozilla } \\
\text { Factory } \\
\text { Space }\end{array}$ & & $x$ & $x$ & Furniture Design \\
\hline Domoticz & $x$ & $x$ & & Home Automation \\
\hline $\begin{array}{l}\text { home- } \\
\text { assistant }\end{array}$ & $x$ & $x$ & & Home Automation \\
\hline Aker & & & $x$ & Food Growing \\
\hline OpenAg & $x$ & $x$ & $x$ & Food Growing \\
\hline Sunzilla & $x$ & $x$ & $x$ & Solar Energy panels \\
\hline $\begin{array}{l}\text { Caminos } \\
\text { de Agua }\end{array}$ & $x$ & $x$ & $\mathrm{X}$ & Water solutions \\
\hline
\end{tabular}

To evaluate the cases, we first linked all the six indicators to related Sustainable Development Goals (SDGs). Each indicator was associated to the temporal dimensions (present and future), and the four principles of openness, namely Transparency (TR), Accessibility (AC), Replicability (RE) and Modularity (MO). Then, we familiarized with all the available data of the selected cases. For the present context and for each case, three values were considered, -1 for negative, 0 for neutral and +1 for positive performance. For an optimum future scenario, the same principles were considered. After that, a set of pathways to optimize the use of $O D$ in a developing country context was developed. The selected cases are introduced next.

\section{OPENDESK}

OpenDesk is a London based company which distributes furniture designs under Creative Commons license, mainly under non-commercial restrictions. The designs are distributed to end-users as a DIY digital fabrication file or to local manufacturers, which produce them commercially. When local manufacturers produce the furniture, the amount paid by the consumer is distributed between the maker, the designer and OpenDesk. The documentation uses .DXF files for generating CNC-milling paths and .PDF files with general instructions.

\section{MOZILLA FACTORY SPACE}

Designed by Nosigner, Mozilla Factory Space is a office based in Tokyo which is part of the Mozilla Foundation. The Foundation is known for the development of OpenSource softwares and solutions for the web. The office design adopted the concept of Open Design and all the furniture project details are made publicly available in .DXF, .PDF and .EPS files. The documentation is given in form of assembly instructions and drawing details for CNC-milling. 


\section{DOMOTICZ}

Domoticz develops open source home automation platform which operates in various Operating Systems, proprietary or not. The documentation is provided in form of instructions for installation, setup, customization and operation. Stable and Beta installation packages are provided and the source code is available at Github. The initiative does not develop any hardware component; however, it provides a list of compatible components, e.g., weather and temperature sensors. Lastly, a forum is provided for community support.

\section{HOME-ASSISTANT}

Similar to Domoticz, Home-assistant is a platform for home automation based on Raspberry $\mathrm{Pi}$. The documentation is also given in form of instructions for installation, setup and operation. It supports integration of over 1000 hardware and software components including sensors, switches, cameras, alarms and presence sensors. Instructions for integrating the components to the platform is given individually. The development community feeds a repository of examples on how to use the home-assistant and a forum provides support for users.

\section{AKER}

Aker develops garden kits for urban farming under a Creative Commons Sharealike 4.0 license. There are no commercial restrictions applied, however any modification or optimization to the original design should be distributed under the same license. Documentation is distributed in .DXF files for CNC-milling and assembly instructions are also provided. The company website provides a community forum for users. Lastly, it is also possible to buy the kits directly from the company.

\section{OPEN AGRICULTURE INITIATIVE (OPENAG)}

OpenAg is an initiative hosted at the MIT Media Lab. Its mission is to "create healthier, more engaging, and more inventive future food systems." (Open Agriculture Initiative, 2016a). Currently, there are several projects under development. For the purposes of this study we will focus on the Personal Food Computer project. It is a small sized and controlled environment platform for growing food. Documentation is available in .DXF, .SLDPRT, .PDF file formats for CNC-Milling and 3D-Printing. A Bill of Materials is provided for electronic components. Instructions and a Community Forum is also available for discussion

\section{SUNZILLA}

Sunzilla is an Open Source solar-powered generator for off-grid supply licensed under a Creative Commons Attribution-Sharealike 2.5 license. Documentation is not available at the Company's webpage. However, it is possible to access it at Instructables or Wikifab repositories. It consists on .PDF and .DXF files for lasercutting or CNC-Milling. We were not able to identify the existence of a forum for development collaboration or discussion.

\section{CAMINOS DE AGUA}

Caminos de Agua is a nonprofit organization located in Mexico which develops solutions for safe water supply and consumption. The organization has over 100 projects implemented in Mexico mostly based on Rainwater Harvesting Systems and Ceramic Filters. No CAD documentation is available at the Organization's Webpage, however .PDF files are available with instructions for building Ceramic Filters, Rainwater Harvesting Systems and Biochar filters.

\section{FINDINGS AND DISCUSSION}

Table 4 presents a summary of our findings. It consists on the evaluation of each case considering the nine indicators previously mentioned. Table five summarizes main current issues identified and a set of recommendations for improving OD projects in terms of openness, social inclusiveness, economic viability and environmental responsibility.

Table 4 - Summary of the findings.

\begin{tabular}{|c|c|c|c|c|c|c|c|c|}
\hline Sustainable Aspects & $\begin{array}{l}\frac{r}{\omega} \\
\stackrel{0}{0} \\
\frac{0}{0} \\
\frac{0}{0}\end{array}$ & $\begin{array}{l}\stackrel{\varpi}{\bar{N}} \\
\stackrel{O}{\Sigma}\end{array}$ & $\begin{array}{l}\stackrel{N}{*} \\
\stackrel{\circ}{0} \\
\text { ○ }\end{array}$ & 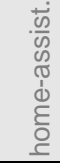 & 高 & $\begin{array}{l}\text { O } \\
\frac{1}{\Phi} \\
\text { O̊ }\end{array}$ & $\begin{array}{l}\stackrel{\varpi}{\bar{N}} \\
\stackrel{5}{J} \\
\text { क }\end{array}$ & 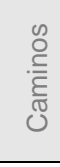 \\
\hline $\begin{array}{l}\text { Does it require } \\
\text { specialized skills for } \\
\text { implementation? }\end{array}$ & -1 & 1 & -1 & -1 & -1 & -1 & -1 & 1 \\
\hline $\begin{array}{l}\text { Does it stimulate the } \\
\text { creation of local jobs } \\
\text { and companies? }\end{array}$ & 1 & 0 & 1 & 1 & 1 & 0 & 1 & 1 \\
\hline $\begin{array}{l}\text { Does it improve } \\
\text { access to basic } \\
\text { services (water, } \\
\text { energy and food)? }\end{array}$ & 0 & 0 & 1 & 1 & 1 & 1 & 1 & 1 \\
\hline $\begin{array}{l}\text { Does it stimulate } \\
\text { sustainable } \\
\text { consumption of natural } \\
\text { resources? }\end{array}$ & 0 & 1 & 0 & 0 & 0 & 0 & 1 & 1 \\
\hline $\begin{array}{l}\text { Does it increase } \\
\text { energy efficiency? }\end{array}$ & 1 & 1 & 1 & 1 & 1 & -1 & 1 & 1 \\
\hline \multicolumn{9}{|l|}{ Openness Principles } \\
\hline Is it Modular? & 0 & 1 & 1 & 1 & 1 & 0 & 0 & 0 \\
\hline Is it Replicable? & 1 & 1 & 1 & 1 & 1 & -1 & 1 & -1 \\
\hline Is it Accessible? & -1 & 0 & 1 & 1 & 0 & 1 & -1 & -1 \\
\hline Is it Transparent? & 0 & 0 & 1 & 1 & 0 & 1 & -1 & 0 \\
\hline TOTAL & 1 & 5 & 6 & 6 & 4 & 0 & 2 & 3 \\
\hline
\end{tabular}

The evaluation process considered the application of the OD cases in a developing country context. More specifically, we addressed it based on our knowledge, experience of the Brazilian availability of materials, tools, machines and skilled professionals. We also explored the existing discussion forums to identify if projects were already developed in Brazil. For example, Home Automation components to assembly Domoticz and Home-assistant projects are easier to find if compared to OpenAg components. At OpenAg forum, for instance, one of the users highlights the need to adapt parts to the project because of some components unavailability (OpenAg Forum 2016b).

In Table 5, we summarize the current characteristics found in the OD cases. We highlight current limitations and present positive aspects. The second column introduces recommendations for developing a pathway for 
addressing such limitations and guaranteeing full democratization of OD. Following Table 5, we will introduce and discuss our findings based on the nine indicators.

Table 5 - Current aspects on OD and future recommendations.

Current Aspects of Open Design Future recommendations

- Cases demand specialized skills, especially in computer programming, electronics and $\mathrm{CAD}$ design. Language is a barrier.

- The OD cases enable favourable environment for creating local jobs.

- Cases are either dependent on high technology or frugal innovations. However, it is important to highlight the potential of home automation for improving access to basic services.

- Energy efficiency increases because of decentralized production processes which reduces the need for transportation. However, the energy source requires

particular attention.

- Modularity was perceived in cases which are scalable and adopt recycling and reusing practices. Modularity in digital domain cases is higher than physical cases.

- Replicability is considerable

high among the cases analysed. Restrictions are limited due to

the lack of information or components not easily available in developing countries

- Proprietary file formats restricts the access to source

files. A more problematic aspect is the use of restricting licenses and the inexistence of open processes for collaboration in cases which commercially

explore the final product.

- Transparency is restricted when missing information for production and assembling is provided. Some of the cases do not have the full documentation available at the project's host page.

\section{SOCIAL INCLUSIVENESS}

A number of studies present successful cases of how OD improved design democratization (von Hippel, 2005; Kwon \& Lee, 2017). However, our findings show that OD is dependent on the existence of skilled professionals, tools and machinery. In a developing country context, this dependency might restrict the adoption of an OD project if such structures are not available at the local level. It increases the costs involved in producing an OD artefact (material acquisition, transportation, rates for tools use). This is particular true for rural communities and small cities. As expected, solutions based on material recycling and reutilization (Mozilla Factory Space and Caminos de Agua) are easier to be replicated in different contexts.
However, incomplete or inaccurate documentation, such as we observed in Caminos de Agua solutions, limits the correct implementation of such OD solutions.

At large, OD projects are linked to digital fabrication processes which we already pointed as a limiting factor for social inclusiveness. At the same time, we add here a less debated aspect in OD communities: the language barrier. It was not surprising that English is the most common language used in collaboration processes and design documentation. Should OD projects stimulate the generation of ramifications in other languages? We believe so, especially if we consider that in developing countries English is not spoken by the Majority of the Population. In Brazil, for instance, English speakers represent $5 \%$ of the total population (British Council, 2014).

Lastly, we envision better possibilities because of the expansion of local Fablabs and Makerspaces supported by Educational Institutions (Blikstein \& Krannich, 2013), and the development of OD manufacturing tools, such as RepRap, a self-replicating 3D printer. We also suggest the adoption of OD processes by professionals in the construction sector. We understand it as an alternative to proximate them to those who are not seeing as usual clients. Self-construction, for instance, is a widespread practice in developing countries (Monteiro et al., 2006). In this sense, OD could guarantee better designed solutions for new or incremental projects.

\section{ECONOMIC VIABILITY}

Economic viability relates both to the commercial viability and to the financial benefits of adopting OD. From the commercial viability perspective, OD stimulates new businesses models (Saebi \& Foss, 2015; Laplume, Anzalone \& Pearce, 2016) focused on services instead of manufacturing. OpenDesk, for instance, distributes furniture design projects for personal use at no cost. However, they offer services for projects customization and linking final consumers to local makers, i.e., specialized places for digital fabrication. Other possibilities are envisioned if we consider, for example, homeautomation services based on Open Source projects like Domoticz and Home-Assistant. We also understand that the adoption of OD by the public sector would contribute to the expansion of small scale manufacturers and to the economic sustainability of such projects.

From the user perspective, the financial benefits are also linked to the availably of infrastructure for manufacturing OD artefacts. At the same time, most of the cases we observed do benefit users in financial terms. Sunzilla and Caminos de Agua minimize costs for access to energy and water while OpenAg and Aker enables food production. Finally, automation projects can increase energy efficiency controlling, for instance, room temperatures and light intensity.

\section{ENVIRONMENTAL RESPONSIBILITY}

We noted that OD cases have benefic potential to optimize energy and natural resources consumption. Decentralized production minimizes the need for transportation which decreases energy consumption and greenhouse gas emissions. Again, this condition is strengthened if local materials are available. Energy is

5 
also benefited from digital domain solutions, such as Domoticz, Home-Assistant and Sunzilla. The first two enable the user to measure energy consumption and automate lighting operations, for instance. Sunzilla provides solar energy panels at relatively low-cost production.

OpenDesk and Aker stimulate the use of sustainable materials by producing artefacts using certified wood panels. This is possible if the production is controlled by the companies. But there are no restrictions applied to the use of non-certified wood by final users. At the same time, there are no artefacts designed to minimize material consumption in both cases. The possibility of disassembly and subsequent use in other projects is also not supported. The Mozilla Factory Space (MFS) and Caminos da Agua, on the other hand, stimulate recycling and reutilization practices. MFS projects use everyday materials like plastic boxes and pallets to function as plant pots or elevated floor tiles. Although it uses plastic objects, we understand it as beneficial once it enables recycling and reutilization processes.

Despite such benefits, we identify the need for quantitative approaches to measure energy efficiency and material consumption impact. In this sense, the development of open data repositories to measure carbon footprint, for example, could help designers to choose the best materials for specific locations in terms of environmental impact.

\section{MODULARITY, REPLICABILITY, TRANSPARENCY AND ACCESSIBILITY}

Although there is no definitive definition for Open Design, we understand openness as a gradual concept. It considers aspects of documentation format, design processes and license attribution. Generally speaking, OD projects based on the digital domain are usually more Open than those based on the physical domain. Table 4 shows that such projects tend to address all principles of openness better than physical designs. This is not an unexpected result. The sharing of information and collaborative processes are easier to be performed in virtual environments, require less financial support and have well-structured platforms for collaboration. Existing platforms still do not meet the needs for collaboration in artefact design.

Modularity is already addressed in OpenSourcre software development. In Domoticz and Home-assistant examples, modularity significantly improves the compatibility to other existing components. Besides that, it allows contributors to focus on very specific issues (Bonaccorsi \& Rossi, 2003; Narduzzo \& Rossi, 2008) but also facilitate the adjustment of design specifications to local standards (language and components), enable design scalability (Aker) and cradle-to-cradle processes. Although some cases presented certain degree of modularity, if we consider joints specification (OpenDesk) and the use of smaller components (Sunzilla), we classified them as neutral because there was no available information related to modularity.

Replicability was well addressed by most of cases. The reasons are that the needed documentation for producing, assembling and operating the design artefacts, and installing the digital cases, were easily available for download. Limitations apply to Sunzilla and Caminos de Agua. Sunzilla did not enable ways to obtain the design documentation at their project's page. Source files and instructions were found in a repository for DIY projects. The case of Caminos de Agua is less critical once it shares construction instructions for producing their projects, but some of the instructions are incomplete.

Accessibility of OD is limited due to the use of proprietary file formats and software. Some Opensource software's are capable of importing different file formats however, such process is never completely reliable and might demand further adjustments to the imported documentation. Another aspect to consider is licensing restrictions for commercial purposes. The restrictions are conflicting to openness principles which guarantee source documentation publicity for anyone and for any purpose (Open Knowledge Foundation, 2012). Lastly, some projects are not open for collaboration processes which minimizes the potential for innovative approaches, modularity and adaptations to the original design.

Transparency is well observed in projects which stimulate the existence of community forums for design development, discussions and inquiries about functionalities. In this sense, Domoticz, Home-Assistant and OpenAg are particular transparent. Cases which are commercially explored presented lower degree of transparency. We consider it as a possible coincidence which should be further investigated. However, the lack of transparency deserves attention once it goes against the OD philosophy.

\section{RESEARCH LIMITATIONS}

We highlight the limitations of our study based on the number of cases we investigated. Furthermore, deeper investigation of the selected cases would be necessary to confirm or contradict these preliminary findings. We draw two observations related to our study. First, our qualitative indicators for social inclusiveness, economic viability and environmental responsibility was built based on the SDGs. We suggest the use of quantitative measurements tools as an alternative to obtain more consistent results although they restrict general observations. Second, the openness principles are already adopted in literature. Transparency and Accessibility principles are present in OD definition if we consider, collaborative processes and access to full documentation design. Replicability and Modularity, on the other hand, are less obvious and might be subject to the researchers' points-of-view. These issues can be addressed by immersive and practicebased researchers or through the development of quantitative measurements.

\section{CONCLUSION}

In this study we present OD cases related to Architecture and Urban Design. We adopted a non-restrictive approach to both sectors to include most of the cases we initially found. This study is a first attempt to understand the current limitations to a widespread adoption of OD in developing countries by the construction sector, including architects, urban designers, other professionals and 
amateurs. We also present a set of initiatives transpose such limitations in future contexts.

We consider several possibilities for further exploration. OD enables new forms of businesses and changes in traditional professional practices. The actual economic benefits for professionals and consumers is a subject to be explored in future studies. Social inclusiveness and environmental responsibility depend on higher democratization processes and data availability. Consequently, the development of tools and collaboration platforms are needed to improve the quality of the OD ecosystem.

\section{AKNOWLEDGEMENTS}

"This study was financed in part by the Coordenação de Aperfeiçoamento de Pessoal de Nível Superior - Brasil (CAPES) - Finance Code 001"

\section{REFERENCES}

Afuah, A., \& Tucci, C. L. (2012). Crowdsourcing as a solution to distant search. Academy of Management Review, 37(3), 355-375.

Balka, K. (2011). Open Source Product Development: the meaning and relevance of openness. (Doctoral dissertation). Retrieved from: http://link.springer.com/book/10.1007\%2F978-3-8349-6949-1

Blikstein, P., \& Krannich, D. (2013). The makers' movement and FabLabs in education: experiences, technologies, and research. In Proceedings of the 12th International Conference on Interaction Design and Children (pp. 613616). ACM.

Boisseau, É., Omhover, J.-F., \& Bouchard, C. (2018). Opendesign: A state of the art review. Design Science, 4.

Bonaccorsi, A., \& Rossi, C. (2003). Why open source software can succeed. Research Policy, 32(7), 1243-1258.

Bonvoisin, J. (2016). Implications of open source design for sustainability. In Sustainable Design and Manufacturing 2016 (pp. 49-59). Springer.

Bonvoisin, J., Galla, J. K., \& Prendeville, S. (2017, April). Design Principles for Do-lt-Yourself Production. In International Conference on Sustainable Design and Manufacturing (pp. 77-86). Springer, Cham.

British Council. (2014). Learning English in Brazil: understanding the aims and expectations of the Brazilian emerging middle classes. São Paulo: British Council.

Elkington, J. (1998). Cannibals with forks: The triple bottom line of sustainability. Gabriola Island: New Society Publishers.

Fjeldsted, A., Adalsteinsdottir, G., Howard, T. J., \& McAloone, T. (2012). Open source development of tangible products. In DS 71: Proceedings of NordDesign 2012, the 9th NordDesign conference, Aarlborg University, Denmark. 22-24.08. 2012.

Hyysalo, S., Kohtala, C., Helminen, P., Mäkinen, S., Miettinen, V., \& Muurinen, L. (2014). Collaborative futuring with and by makers. CoDesign, 10(3-4), 209-228.

Kohtala, C. (2015). Addressing sustainability in research on distributed production: an integrated literature review. Journal of Cleaner Production, 106, 654-668.

Kwon, B.-R., \& Lee, J. (2017). What makes a maker: the motivation for the maker movement in ICT. Information Technology for Development, O(0), 1-18. https://doi.org/10.1080/02681102.2016.1238816
Lakhani, K. R., \& Panetta, J. A. (2007). The principles of distributed innovation. Innovations: Technology, Governance, Globalization, 2(3), 97-112.

Laplume, A., Anzalone, G. C., \& Pearce, J. M. (2016). Opensource, self-replicating 3-D printer factory for small-business manufacturing. International Journal of Advanced Manufacturing Technology, 85(1-4), 633-642. https://doi.org/10.1007/s00170-015-7970-9

Levanen, J., Hossain, M., Lyytinen, T. (2016). Implications of frugal innovations on sustainable development: Evaluating water and energy innovations. Sustainability (Switzerland), 8(1), 1-17.

Monteiro, E. Z., de Mattos Moreno, M., Pina, S. A. M. G., Labaki, L. C., Kowaltowski, D. C., da Silva, V. G., \& de Oliveira, M. C. A. (2006). A sense of comfort in open space around ownerbuilt houses: the case of Campinas, Brazil. In PLEA 200623rd International Conference on Passive and Low Energy Architecture, Conference Proceedings.

Narduzzo, A., \& Rossi, A. (2008). Modularity in action: GNU/Linux and free/open source software development model unleashed. Department of Computer and Management Sciences, University of Trento, Italy.

Nascimento, S. (2014). Critical Notions of Technology and the Promises of empowerment in shared machine shops. Journal of Peer Production, (5). Retrieved from http://peerproduction.net/issues/issue-5-shared-machineshops/editorial-section/critical-notions-of-technology-and-thepromises-of-empowerment-in-shared-machine-shops/

Nielsen, K., Jørgensen, K. A., Taps, S. B., \& Petersen, T. D. (2011). Supporting sustainability and personalization with product architecture. In MCPC 2011 World Conference on Mass Customization and Personalization.

Open Agriculture Initiative (2016a). Overview. Retrieved from: https://www-prod.media.mit.edu/groups/open-agricultureopenag/overview/

Open Agriculture Initiative (2016b). User discussions. Retrieved from: https://forum.openag.media.mit.edu/t/where-are-youbuilding-your-food-computer/16/52

Open Knowledge Foundation. (2012). 'No Title'. The Open Design Definition v. 0.5. Retrieved from: https://github.com/OpenDesign-WorkingGroup/Open-DesignDefinition/blob/master/open.design_definition/open.design.de finition.md.

Raasch, C., Herstatt, C., \& Balka, K. (2009). On the open design of tangible goods. $R$ and D Management, 39(4), 382-393. https://doi.org/10.1111/j.1467-9310.2009.00567.x

Saebi, T., \& Foss, N. J. (2015). Business models for open innovation: Matching heterogeneous open innovation strategies with business model dimensions. European Management Journal, 33(3), 201-213. https://doi.org/10.1016/j.emj.2014.11.002

Shah, S. K. (2008). Open Beyond Software. In M. Cooper, Danese. DiBona, Chris. Stone (Ed.), Open Sources 2.0 (1st ed., pp. 1-28). Sebastopol.

Vallance, R., Kiani, S., \& Nayfeh, S. (2001). Open design of manufacturing equipment. ... on Agile, Reconfigurable Manufacturing, ..., 1-12. Retrieved from http://diyhpl.us/ bryan/papers2/open-source/Open design of manufacturing equipment.pdf

von Hippel, E. (2005). Democratizing Innovation-The MIT Press (2005). Cambridge: MIT Press.

SDGs, U. N. (2015). United Nations Sustainable Development Goals. Retrieved https://www.un.org/sustainabledevelopment/

West, J., \& O'Mahony, S. (2008). The role of participation architecture in growing sponsored open source communities. Industry and Innovation, 15(2), 145-168. https://doi.org/10.1080/13662710801970142 